\title{
Structures of snow cloud in dry-snow avalanches
}

\author{
K. NishimuRa, N. Maeno, \\ Institute of Low Temperature Science, Hokkaido University, Sapporo 060, Japan \\ K. KAWADA, \\ Toyama University, Toyama 930, Japan \\ K. IZUMI \\ Research Institute for Hazards in Snowy Areas, Nïgata University, Niigata 950-21, Japan
}

\begin{abstract}
During two winter seasons, we observed avalanche winds and the air movement in the snow dust region. The wind velocity near the avalanche front was comparable to the averaged internal velocity of the front region. The avalanche wind blew down the valley. However, there was a rising air current just before the avalanche front. The wind velocity and direction showed a periodic change in the snow cloud region, from which the size of the ordered structure (vortex) was estimated to be $35-70 \mathrm{~m}$. The density of the frontal part of one avalanche was estimated to be $1.9-3.8 \mathrm{~kg} \mathrm{~m}^{-3}$.
\end{abstract}

\section{INTRODUGTION}

Both impact pressures and front velocities of powder snow avalanches have been measured frequently, but only a few attempts have been made to investigate the internal structure (McClung and Schaerer, 1985; Salm and Gubler, 1985; Nishimura and others, 1989). In particu- lar, very little information is available on the snow cloud (snow dust) region and the wind which precedes the avalanche front.

This paper gives new findings about avalanche wind and structures in the snow cloud region obtained by analysis of data from three avalanches in 1991 and 1992 in the Shiai-dani valley.

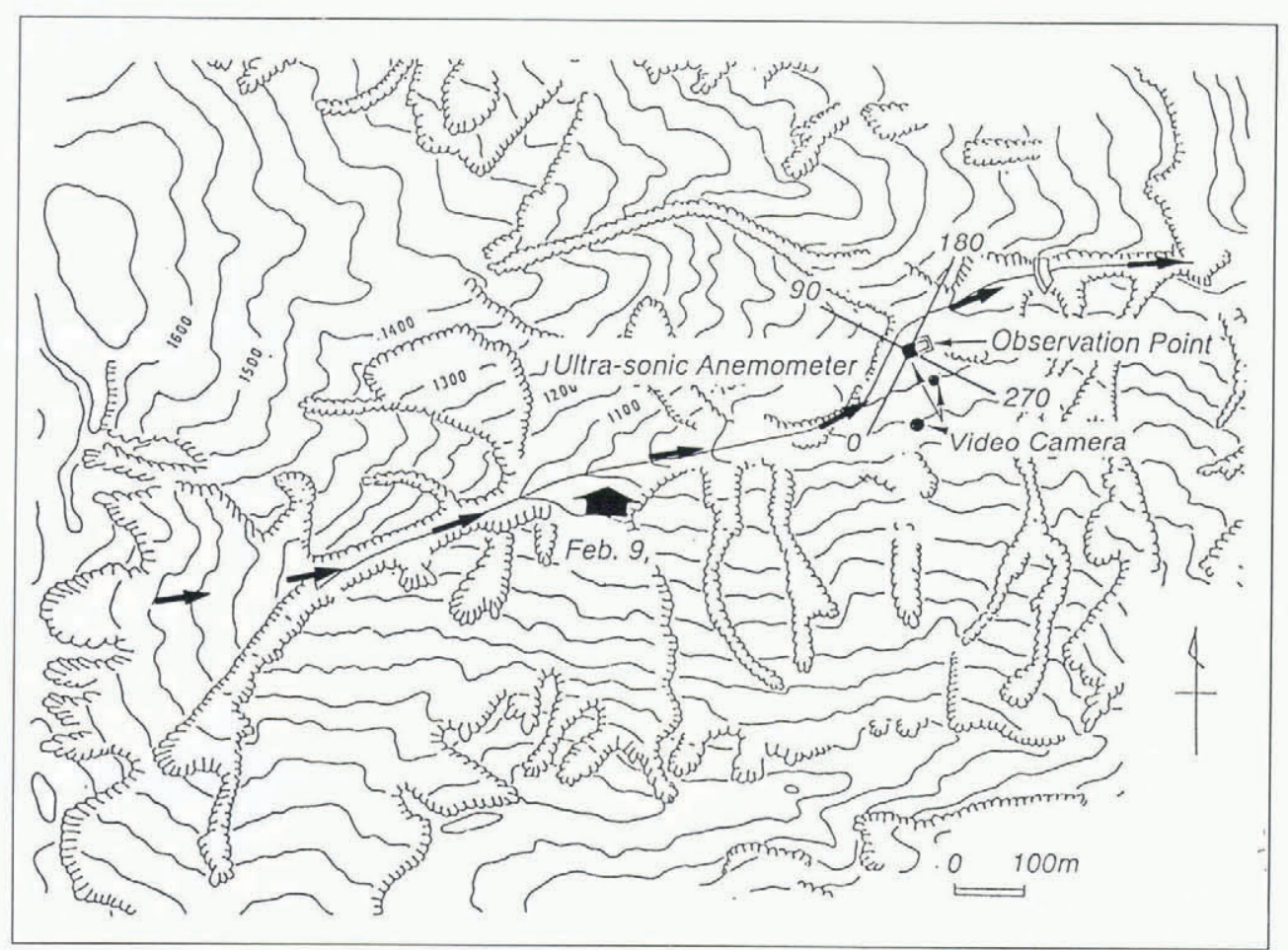

Fig. 1. Location of the observation site in the Shiai-dani region. Most avalanches flow along the line indicated by small arrows. Avalanche $C$ was observed to flow from the branch, as marked by the large arrow. 


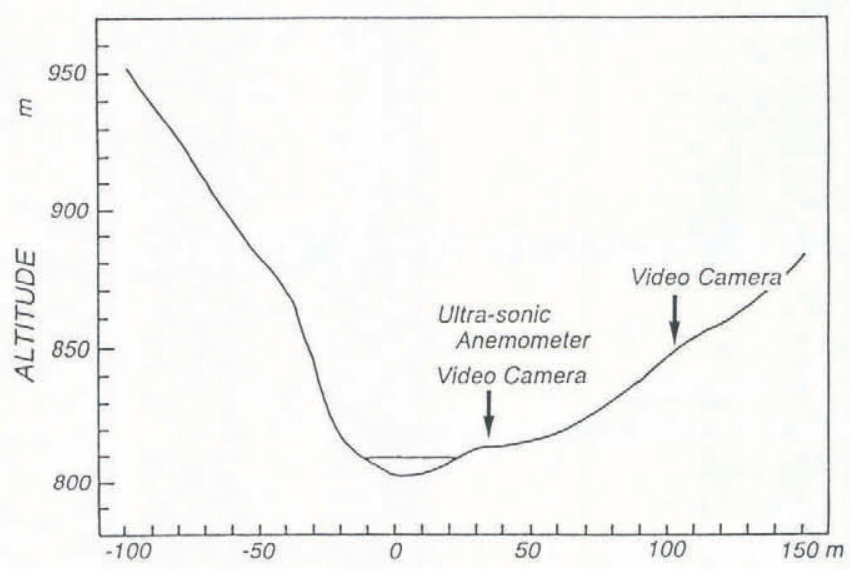

Fig. 2. Cross-section of the observation site.

\section{MEASUREMENTS}

The climate of the Shiai-dani in the Kurobe Canyon area is characterized by heavy snow falls in wintertime. Snow usually accumulates up to about $4 \mathrm{~m}$ at terraces and more than $20 \mathrm{~m}$ in valleys. Air temperature varies between $-10^{\circ}$ and $+5^{\circ} \mathrm{C}$ in a cold winter season (Kawada and others, 1989).

The location of the observation site in the Shiai-dani region and the cross-section of it are shown in Figures 1 and 2, respectively. Shiai-dani originates at an elevation of $1600 \mathrm{~m}$ a.s.l. and terminates at the junction with the Kurobe River at the elevation of $600 \mathrm{~m}$; its length is $\sim 2000 \mathrm{~m}$, the elevation difference is $\sim 1000 \mathrm{~m}$, and angle of inclination $\sim 33^{\circ}$. At the main observation site at the midpoint of the avalanche path, instruments were set to make various measurements, including impact pressure, temperature, air pressure, avalanche wind, and ground vibration (seismicity). There were also three video cameras. Impact pressures were measured with straingauge type load cells attached to $10 \mathrm{~cm}$ diameter pressure plates. Three load cells were sited at heights of 2.60, 3.56, and $4.33 \mathrm{~m}$ above the ground. The avalanche wind was measured with an ultrasonic anemometer which was able to sense both horizontal and vertical components of the

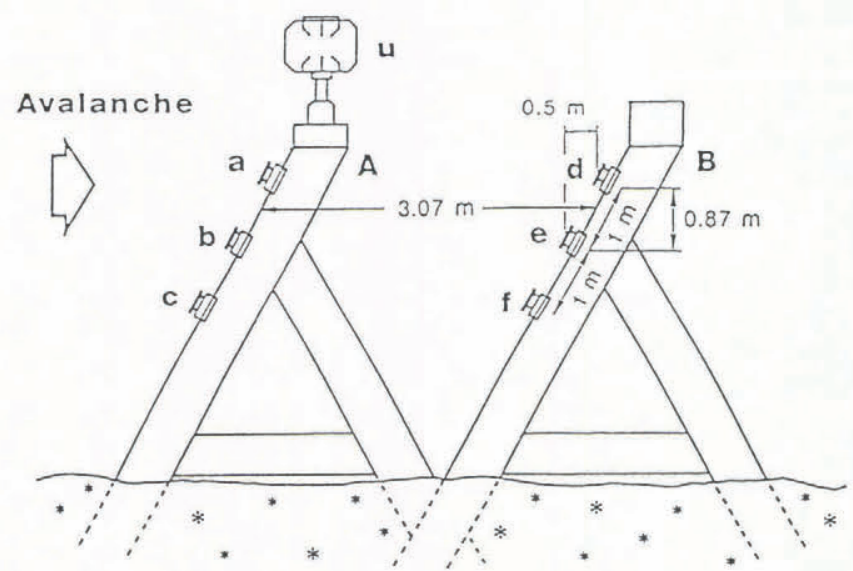

Fig. 3. Schematic representation of the measuring apparatus set in an avalanche chute. $a, b$, and $c$ are load cells installed on the mound $A$, and $d, e$, and $f$ are those on the mound $B . u$ is an ultrasonic anemometer. wind. Further, the wind pressure was observed with a strain-gauge type transducer $8.0 \mathrm{~cm}$ in diameter. Most of the equipment was installed on two sets of steel mounds formed of cylinders $0.3 \mathrm{~m}$ in diameter and $5 \mathrm{~m}$ in height (Fig. 3). All the data were recorded by an analog datarecorder located in a room in an underground tunnel. More detailed information on the measurement system has been reported by Kawada and others (1989) and Nishimura and others (1989).

\section{RESULTS}

During two winter seasons from 1990-92, seven avalanches crossed the observation site. In this paper we present three examples and examine their internal structures.

\section{Avalanche A (5 February 1991)}

Figure 4 shows the recording of impact pressure, wind velocity and ground vibration during the passage of an avalanche which took place at $0458 \mathrm{~h}$ on 5 February 1991. Since it happened early in the morning, size, flow height and front velocity could not be recorded by the video camera.

Although the noise level reached a magnitude of about $10 \mathrm{kPa}$, the wave form of impact pressure between 22 and $27 \mathrm{~s}$ suggests that the avalanche was of Type-1 (according to classification scheme of Kawada and others (1989)), which is characterized by a number of discrete sharp peaks.

The wind velocity measured with an ultrasonic anemometer showed abnormal values between 24 and $31 \mathrm{~s}$ and between 42 and $44 \mathrm{~s}$, due to the passage of the snow dust region. Although it is not easy to define the arrival time of the avalanche front, we assume that it arrived at the instrument mounds when the anemometer began to give abnormal signals. Abrupt changes of the
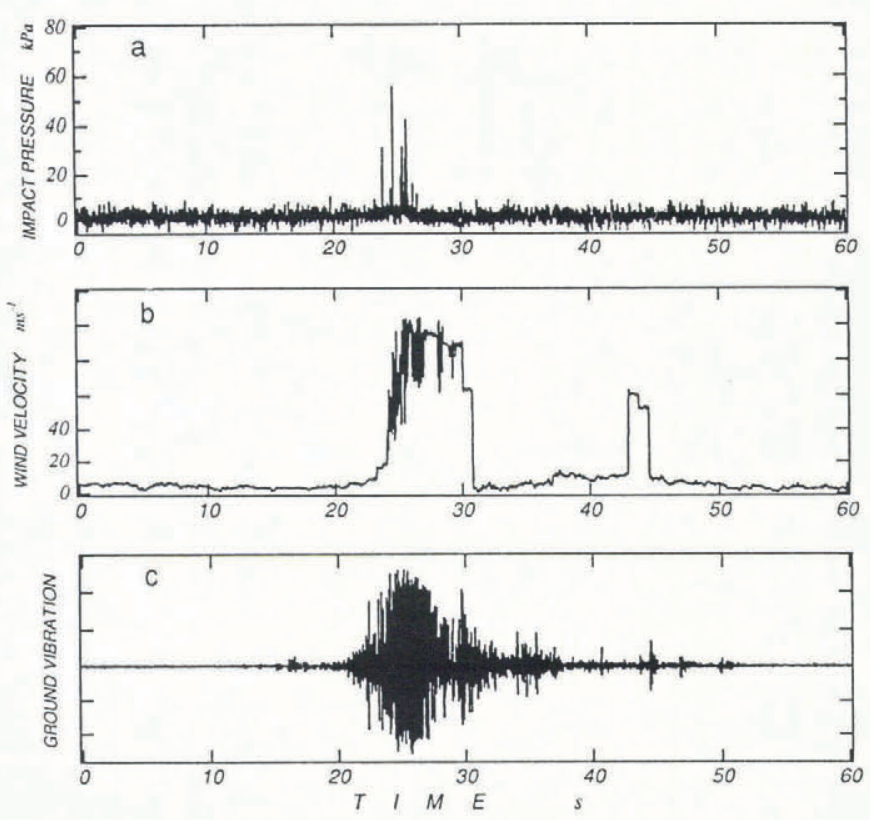

Fig. 4. Recordings in avalanche A (5 February 1991). a, impact pressure; $b$, wind velocity; $c$, ground vibration. 
output between 24 and $31 \mathrm{~s}$ are thought to represent the variation of snow-particle concentration (bulk density) in the snow-cloud region. Figure 4 shows that the snowparticle concentration varied largely in the frontal part of the avalanche (avalanche head) and was rather uniform in the following part. It is important to note that the
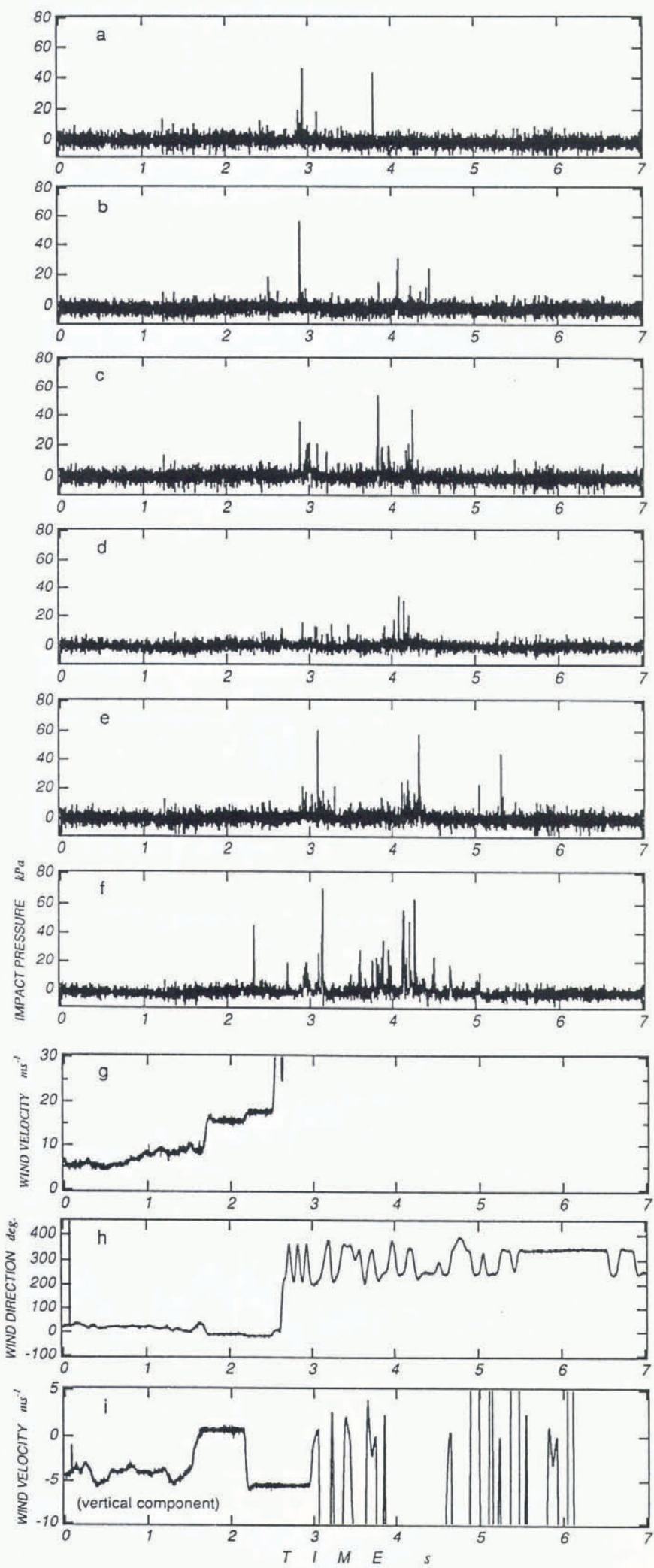

Fig. 5. Recordings in avalanche A (5 February 1991). a$f$, impact forces obtained using the load cells shown in Figure $3 ; g-i$, wind recordings obtained with the ultrasonic anemometer. impact pressure was recorded only in the frontal part (Fig. 4a) and that the magnitudes of ground vibration were also larger there (Fig. 4c). The snow-particle concentration in the snow cloud region decreased enough after $31 \mathrm{~s}$ to transmit the ultrasonic wave and increased again temporarily between 42 and $44 \mathrm{~s}$.

Impact pressure and wind data during the first $8 \mathrm{~s}$ are shown in Figure 5. Figure $5 \mathrm{a}-\mathrm{f}$ gives the impact forces measured by the load cells shown in Figure 3. Sharp peaks in the impact pressure data are thought to represent the impacts of the snow blocks. The numbers of collisions in Figure $5 \mathrm{a}-\mathrm{f}$ were 12, 23, 23, 24, 38 and 55, respectively. If the magnitude of a pressure peak is assumed to show relative number concentrations of snow blocks, it is seen that the density of snow blocks became lower with height at both mounds. In particular at the highest position (Fig. $5 \mathrm{a}$ and d) the number of blocks was nearly halved.

The record of the ultrasonic anemometer (Fig. $5 \mathrm{~g}-\mathrm{i}$ ) showed that wind velocity began to increase about $2 \mathrm{~s}$ before the passing of the avalanche front and reached a maximum of $17.5 \mathrm{~m} \mathrm{~s}^{-1}$. Then it showed abnormal values due to the passage of the snow dust region. The direction of the wind (Fig. 5h) was defined so that the upstream direction of the valley indicates $0^{\circ}$ or $360^{\circ}$, as shown in Figure 1. Then it is obvious in the figure that the avalanche wind blew from roughly downstream along the avalanche chute. The vertical component of the wind velocity (Fig. 5i) became $+0.8 \mathrm{~m} \mathrm{~s}^{-1}$ at $1.5 \mathrm{~s}$ and showed an abrupt change to $-6.0 \mathrm{~m} \mathrm{~s}^{-1}$ which lasted $0.8 \mathrm{~s}$. The positive sign designates upward flow.

After the passage of the avalanche, many snow blocks were observed to form a snow-avalanche debris.

\section{Avalanche B (1 February 1992)}

Figures 6 and 7 show the records of an avalanche at $1837 \mathrm{~h}$ on 1 February 1992. Since it happened in the evening we could not record the visual data with the video cameras. The output of the anemometer showed abnormal values during the passage of the snow dust region in the same manner as in Figures 4 and 5. Further, changes in the wind velocity in the snow cloud (representing the variation of the density) seemed to be large in the frontal part. Avalanche wind began to increase about $1.5 \mathrm{~s}$ before the avalanche front arrived and showed a maximum of $18 \mathrm{~m} \mathrm{~s}^{-1}$ which lasted for $0.8 \mathrm{~s}$. The wind direction of the avalanche wind was $340^{\circ}$, which is also roughly in the downstream direction.

Wind pressure (Fig. 6c) also showed a rapid increase when the mound was covered by the snow cloud. The value reached the maximum of $350 \mathrm{~Pa}$ and then decreased with time. Assuming that the density in the snow cloud region did not change so much, this decrease of the wind pressure may reveal that the wind velocity in the snow cloud was high near the front and diminished gradually afterwards.

The atmospheric pressure (Fig. 6d) measured with a strain-gauge type transducer showed a gradual drop of $4 \mathrm{mb}\left(4 \times 10^{2} \mathrm{~Pa}\right)$ when the avalanche crossed. The gradual return to the original value suggests that the pressure drop was caused by a simple suction.

Impact pressure data for $8 \mathrm{~s}$ (Fig. $7 \mathrm{a}-\mathrm{f}$ ) indicate that 

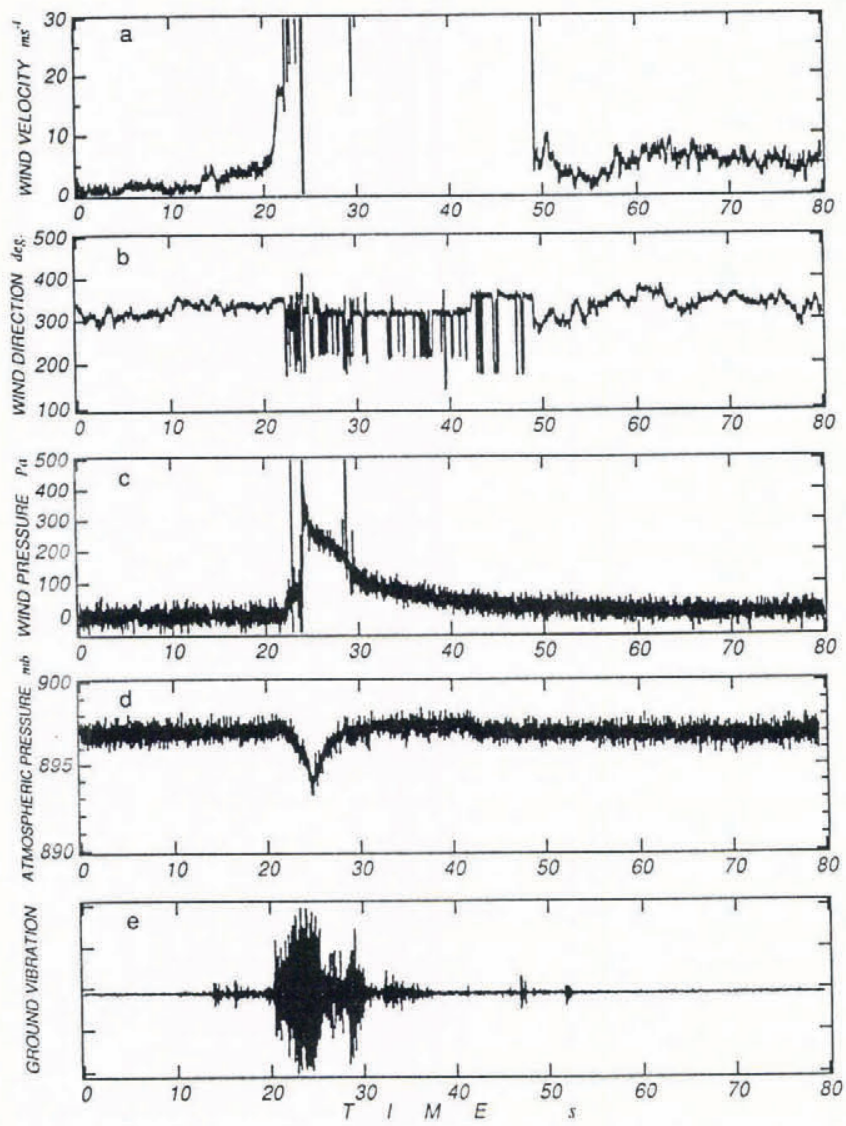

Fig. 6. Recordings in avalanche B (1 February 1992). a, wind velocity; $b$, wind direction; $c$, wind pressure; $d$, atmospheric pressure; e, ground vibration.

the density of snow blocks was higher closer to the snow surface.

\section{Avalanche C (9 February 1991)}

In avalanches $\mathrm{A}$ and $\mathrm{B}$ the densities of the snow cloud region were fairly high, so the recordings of the wind velocity and wind direction in the snow cloud showed abnormal values. But on 9 February 1991 we measured not only the avalanche wind but also the air movement in the snow cloud region. The core regions (snow flowing layer), which were composed of many snow blocks and fluidized snow and considered to form the principal mass of the avalanche, were observed to stop about $200 \mathrm{~m}$ in front of the observation site.

Figure 8 shows the recording of the wind. By means of the video film analysis the front velocity was determined to be $18 \mathrm{~m} \mathrm{~s}^{-1}$ and the period covered with the snow cloud (indicated with an arrow in Figure 8a) was $35 \mathrm{~s}$. The avalanche wind increased gradually for $15 \mathrm{~s}$ and reached $10 \mathrm{~m} \mathrm{~s}^{-1}$. The arrival of the snow cloud is considered to be at $20.3 \mathrm{~s}$ in Figure 8. The initial wind velocity in the snow cloud region was roughly similar to the maximum velocity of the avalanche wind. Then it increased and $4 \mathrm{~s}$ later came up to $12 \mathrm{~m} \mathrm{~s}^{-1}$. In the following $30 \mathrm{~s}$ it declined gradually. Although some fluctuations appeared, average wind directions both in the avalanche wind and in the snow dust were nearly $360^{\circ}$, which corresponds to the upstream of the valley (Fig. $8 \mathrm{~b}$ ). Since
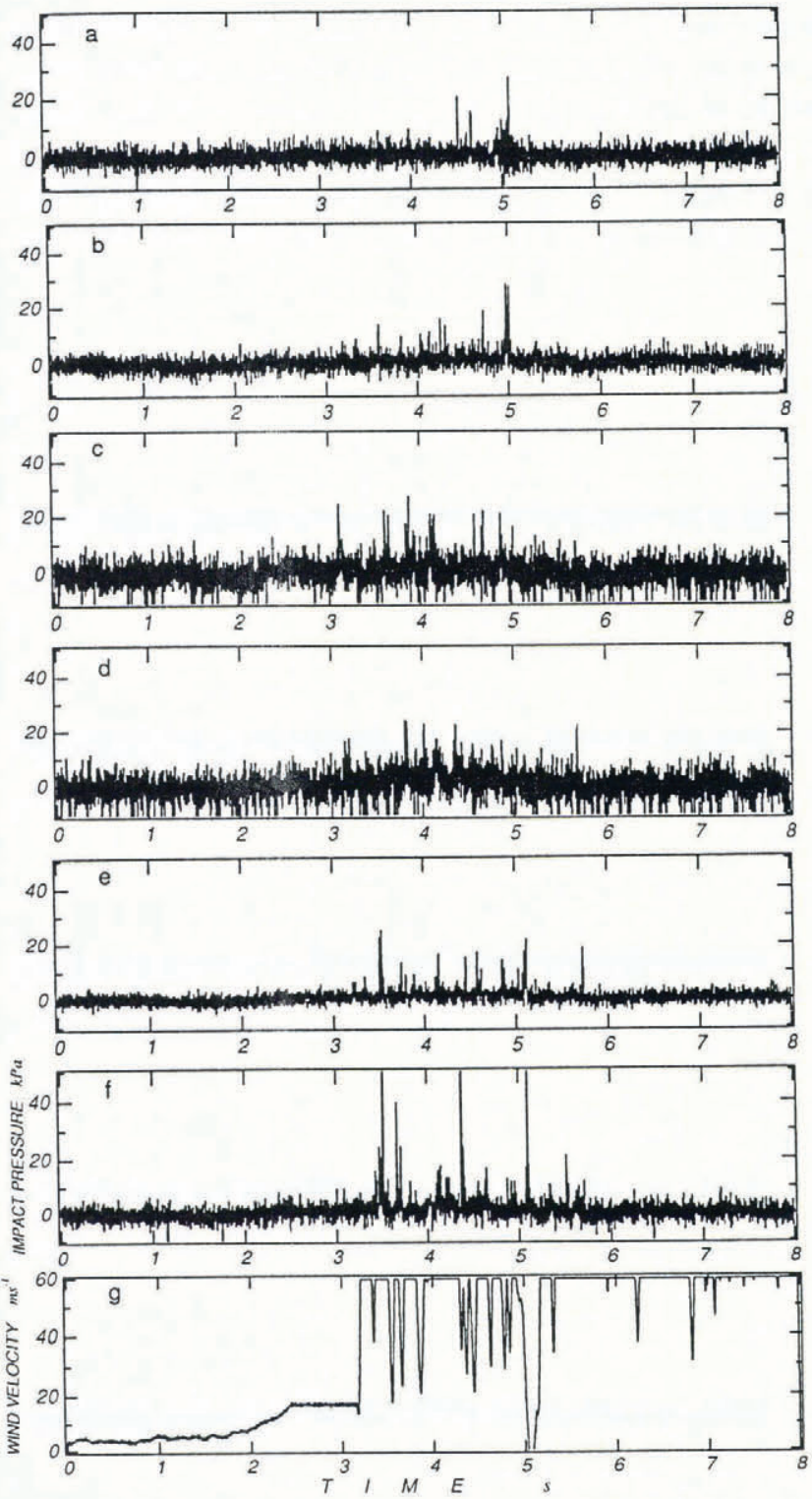

Fig. 7. Recordings in avalanche B (1 February 1992). a$f$, impact pressures; $g$, wind velocity.
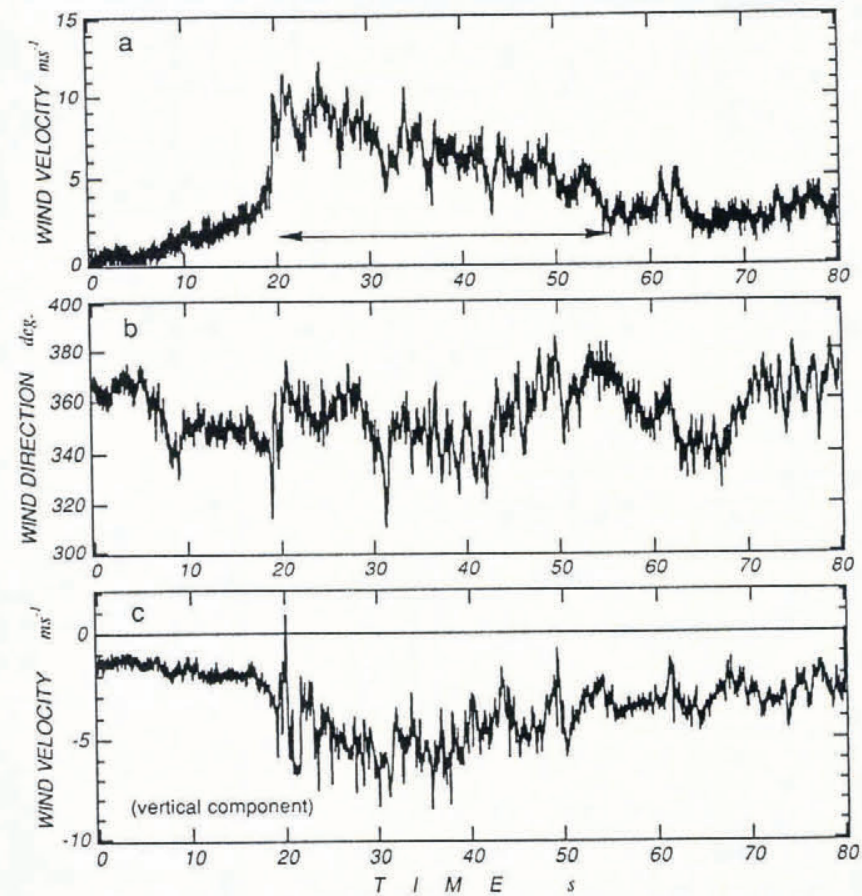

Fig. 8. Wind recordings in avalanche C (9 February 1991). 
the wind blew down the valley, the vertical component of the wind velocity (Fig. 8c) was negative in general, but it became positive near the avalanche front. It is interesting to note that the wind velocity, wind direction and the vertical component of the wind velocity showed the periodic change in the snow cloud region.

The length of the snow dust region was calculated to be about $250 \mathrm{~m}$ assuming that the mean velocity was $7 \mathrm{~m} \mathrm{~s}^{-1}$ (Fig. 8).

\section{DISGUSSION}

The impact-force data recorded by means of the analogue data recorder was transformed into digital values using an A-D converter. The cross-correlation function was calculated at $1.5 \mathrm{~s}$ intervals from a time series of impactforce data (Fig. $4 \mathrm{a}-\mathrm{f}$ and Fig. $7 \mathrm{a}-\mathrm{f}$ ). The average internal velocity was obtained from a combination of the lag time that gave the highest correlation and the distance between the two measuring points. Further details of the method have been given in Nishimura and others (1987). Calculations were carried out for the following pairs: $a-d, b-e$ and $c-f$, and results are presented in Tables 1 and 2 . We can recognize that the wind velocity near the avalanche front was comparable to the averaged internal velocity for the front region. This agrees with the result reported by Nishimura and others (1989) for the avalanche on 3 February 1988. These tables tell us that the internal velocity is slower at the high position than at

Table 1. Internal velocity of avalanche $A$ at $0458 \mathrm{~h}$ on 5 February 1991

Height above ground

Time

$2.0-3.5 \mathrm{~s}$

$3.5-5.0 \mathrm{~s}$

$\begin{array}{lcr}\text { High }(4.33 \mathrm{~m}) & - & 10.3 \mathrm{~m} \mathrm{~s}^{-1} \\ \text { Middle }(3.56 \mathrm{~m}) & 15.2 \mathrm{~m} \mathrm{~s}^{-1} & 12.4 \mathrm{~m} \mathrm{~s}^{-1} \\ \text { Low }(2.60 \mathrm{~m}) & 11.8 \mathrm{~m} \mathrm{~s}^{-1} & 7.1 \mathrm{~m} \mathrm{~s}^{-1}\end{array}$

Table 2. Internal velocity of avalanche $B$ at $1837 \mathrm{~h}$ on 1 February 1992

\begin{tabular}{lcc} 
Height above ground & \multicolumn{2}{c}{ Time } \\
& $2.9-4.4 \mathrm{~s}$ & $4.4-5.9 \mathrm{~s}$ \\
& & \\
\hline & & \\
High $(4.33 \mathrm{~m})$ & $13.6 \mathrm{~m} \mathrm{~s}^{-1}$ & $13.3 \mathrm{~m} \mathrm{~s}^{-1}$ \\
Middle $(3.56 \mathrm{~m})$ & $16.5 \mathrm{~m} \mathrm{~s}^{-1}$ & $24.8 \mathrm{~m} \mathrm{~s}^{-1}$ \\
Low $(2.60 \mathrm{~m})$ & $12.9 \mathrm{~m} \mathrm{~s}^{-1}$ & $14.3 \mathrm{~m} \mathrm{~s}^{-1}$
\end{tabular}

the middle position. As mentioned before, the number of snow blocks at the high position was extremely low. Therefore we can consider that the high position was out of the dense flow region and some saltating blocks over the core hit the sensor during the passage of avalanches. Taking into account the vertical distance of $0.87 \mathrm{~m}$ between adjacent load cells, the vertical velocity shear of the avalanche flow obtained with the low and middle data was estimated to be in the range $4-12 \mathrm{~s}^{-1}$.

The density in the snow dust region was not well known, since it has not been measured directly. Mellor (1978) estimated the snow density to be of the order of $10^{-3}$ to $10 \mathrm{~kg} \mathrm{~m}^{-3}$ based on known mechanical and optical characteristics of wind-blown snow in turbulent suspension. Assuming that the snow cloud behaves as a fluid, the dynamic pressure $P$ is given by $P=0.5 \mathrm{C}_{\mathrm{D}} \rho v^{2}$, where $\mathrm{C}_{\mathrm{D}}$ is a drag coefficient and $\rho$ and $v$ are the density and speed of the snow cloud. Setting pressure at $350 \mathrm{~Pa}$ (Fig. 6), internal velocity at $13.6 \mathrm{~m} \mathrm{~s}^{-1}$ (Table 2) and assuming $\mathrm{C}_{\mathrm{D}}=1-2$ (Prandtl, 1965), the density of the frontal part of the avalanche on 1 February 1992 was estimated to be $1.9-3.8 \mathrm{~kg} \mathrm{~m}^{-3}$. The magnitude obtained is almost comparable to that of dry air, roughly $1.3 \mathrm{~kg} \mathrm{~m}^{-3}$ at $0^{\circ} \mathrm{C}$. The density of the avalanche on 9 February 1991 seemed to be lower, because the ultrasonic waves could be transmitted in the avalanche.

Figure 9 is a schematic showing the cross-sectional wind structure near the avalanche front, based on the data in Figure 8 and taking into account the $30^{\circ}$ average slope near the observation site. There were rising currents just before the avalanche front and the upward motion appeared periodically in the flow. The frequency analysis of this periodic change of the wind is given in Figure 10 showing the power spectrum of the wind velocity and wind direction in the snow cloud region. There is a remarkable peak between 0.1 and $0.2 \mathrm{~Hz}$ in each spectrum of wind velocity and direction, which may suggest ordered, vortex-like structures in the snow cloud. Assuming that the average flow speed is $7 \mathrm{~m} \mathrm{~s}^{-1}$, the size of the structure was estimated to be $35-70 \mathrm{~m}$.

\section{CONCLUSIONS}

A powder snow avalanche, especially in the snow cloud region, is essentially a turbidity current flowing down an incline. Therefore the dynamic behaviours and the internal structures, including the avalanche wind and entrainment process, have been investigated mainly with water tank experiments (Tochen-Danguy and Hopfinger, 1975; Beghin and others, 1981). But due to the

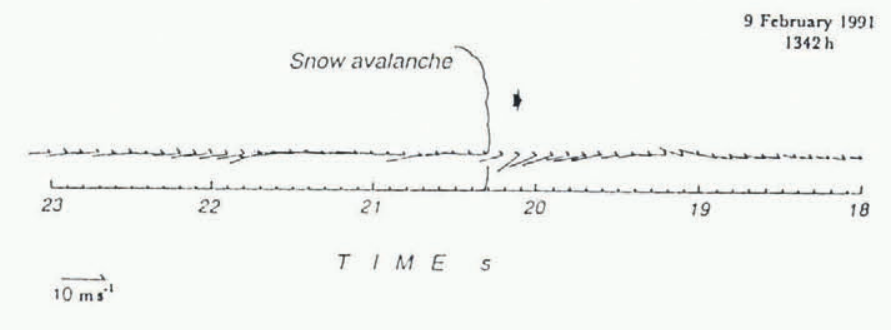

Fig. 9. Schematic cross-section of wind structures near the avalanche front. 

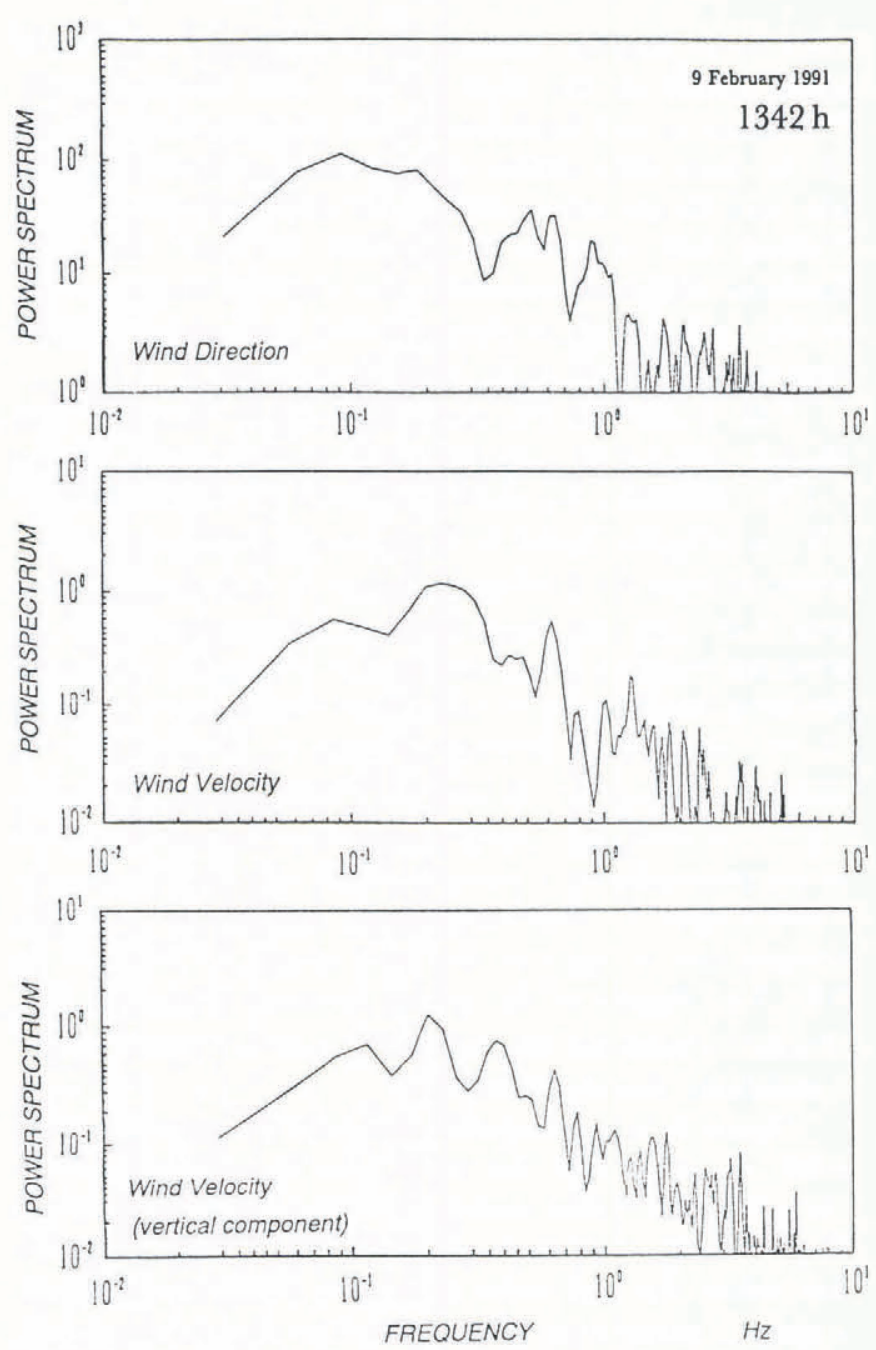

Fig. 10. Power spectrum of the wind in the snow cloud region.

unpredictability of avalanche occurrence, it has been very difficult to obtain a set of reliable field data. At Shiai-dani in the Kurobe Canyon region during two winter seasons from 1990-92, we succeeded in observing not only the avalanche wind but also air movement in the snow dust region, and the following results were obtained.

The wind velocity near the avalanche front was comparable to the averaged internal velocity of the front region, which was obtained from the frequency analysis of the impact pressure data. The avalanche wind blew down the valley, so the vertical component of the wind velocity was negative in general, but rising currents existed just before the avalanche front. The wind velocity, wind direction and the vertical component of the wind velocity showed periodic changes in the snow cloud region. Assuming that average flow speed was $7 \mathrm{~m} \mathrm{~s}^{-1}$, size of the ordered structure (vortex) was estimated to be 35$70 \mathrm{~m}$. The density in the snow cloud region showed fairly large variations in the frontal part of the avalanche and was rather uniform in the following part. The density of the frontal part of the avalanche on 1 February 1992 was estimated to be $1.9-3.8 \mathrm{~kg} \mathrm{~m}^{-3}$.

\section{ACKNOWLEDGEMENTS}

The authors would like to express their gratitude to the following individuals for their helpful co-operation: $\mathrm{K}$. Kosugi and M. Higa (Hokkaido University); H. Iida (Yoshida Science Museum of Kurobe City); A. Sato, O. Abe and Y. Nohguchi (National Research Institute for Earth Science and Disaster Prevention); K. Fujisawa and H. Terada (Civil Engineering Research Institute). They would also like to thank the Kansai Electric Power Company, who supported the project and made every effort with the logistic arrangements for the research operation. This work was partly supported by the Grantin-Aid for Co-operative Research and Science Research of the Ministry of Education, Science and Culture, Japan.

\section{REFERENCES}

Beghin, P., E.J. Hopfinger and R.E. Britter. 1981. Gravitational convection from instantaneous sources on inclined boundaries. F. Fluid. Mech., 107, 407-422.

Kawada, K., K. Nishimura and N. Maeno. 1989. Experimental studies on a powder-snow avalanche. Ann. Glaciol., 13, 129-134.

McClung, D. M. and P.A. Schaerer. 1985. Characteristics of flowing snow and avalanche impact pressures. Ann. Glaciol., 6, 9-14.

Mellor, M. 1978. Dynamics of snow avalanches. In Voight, B., ed. Rockslides and avalanches. Vol. 1. Natural phenomena. Amsterdam, etc., Elsevier, 753-792.

Nishimura, K., N. Maeno and K. Kawada. 1987. Internal structures of large-scale avalanches revealed by a frequency analysis of impact forces. Low Temp. Sci., Ser. A 46, 91-98.

Nishimura, K., H. Narita, N. Maeno and K. Kawada. 1989. The internal structure of powder-snow avalanches. Ann. Glaciol., 13, 207-210.

Prandtl, L. 1965. Führer durch die Stromungslehre. Braunschweig, Friedr. Vieweg \& Sohn.

Salm, B. and H. Gubler. 1985. Measurement and analysis of the motion of dense flow avalanches. Ann. Glaciol., 6, 26-34.

Tochon-Danguy, J.-C. and E.J. Hopfinger. 1975. Simulation of the dynamics of powder avalanches. International Association of Hydrological Sciences Publication 114 (Symposium at Grindelwald 1974 - Snow Mechanics), 369-380.

The accuracy of references in the text and in this list is the responsibility of the authors, to whom queries should be addressed. 